\title{
Phase Transition and Thermal Expansion Behavior of Zirconia Setter Fabricated from Fused CaO Stabilized Zirconia
}

\author{
Ji-Hoon Park ${ }^{* * * *}$, Il-Hwan Bang****, and Sang-Jin Lee $(\mathbb{D} * * * * * * *, \uparrow$ \\ *Research Institute of YJC Co., Ltd, Hampyung 57161, Korea \\ **Department of Advanced Materials and Engineering, Mokpo National University, Muan 58554, Korea \\ ***Jeonnam Advanced Ceramics Center, Jeonnam Technopark, Mokpo 58618, Korea \\ ****The Research Institute of Ceramic Industry Technology in Mokpo National University, Muan 58554, Korea
}

(Received February 5, 2019; Revised February 24, 2019; Accepted March 4, 2019 )

\begin{abstract}
To improve resistance in thermal shock of zirconia setter which is frequently and repeatedly exposed to high temperature, high degree of porosity and control of thermal expansion are needed for which the fused CSZ (CaO stabilized zirconia) is used to produce the zirconia setter. In the present study, the effects of sintering temperature, cool down condition, addition of CaO stabilizer, and addition of other additives on phase transition and thermal expansion behavior of the fabrication process of zirconia setter, were examined. The zirconia setter, fabricated with fused $\mathrm{CSZ}$ at $1550^{\circ} \mathrm{C}$, exhibited $20.4 \mathrm{MPa}$ of flexural strength, $6.8 \%$ of absorbance, and $27.9 \%$ of apparent porosity. The rapid change in thermal expansion of zirconia setter is observed at temperature around $800^{\circ} \mathrm{C}$, and it was reduced by low firing temperature, slowed cooled down, and addition of $\mathrm{CaO}$.
\end{abstract}

Key words : Phase transition, Thermal expansion, Zirconia, CaO stabilizer, Thermal shock

\section{Introduction}

$\mathrm{P}$ ure raw zirconia materials exhibit phase changes according to temperature such as monoclinic phase at room temperature, tetragonal phase at $1,150^{\circ} \mathrm{C}$, and cubic phase at $2,400^{\circ} \mathrm{C}$ wherein the transition from tetragonal phase to monoclinic phase accompanies volumetric change of $3 \sim$ $5 \% .^{1-3)}$ It manifests weak mechanical properties owing to such phase changes, thereby hardly employable as heat resistant or structural materials. ${ }^{3-6)}$ However, the phase change from tetragonal to monoclinic phase is used to improve fracture toughness by decreasing crack propagation energy owing to the absorption of energy at the crack tip by the transition to martensite. ${ }^{7,8)}$ To exploit the phase change of stress-induced martensitic transformation, the attainment of micro-scaled tetragonal phases existing at normal temperature is important. ${ }^{9)}$ Partially stabilized zirconia (PSZ) is fabricated by adding stabilizers such as $\mathrm{MgO}$, $\mathrm{CaO}$, and $\mathrm{Y}_{2} \mathrm{O}_{3}$ to zirconia to make it a cubic phase and then thermally treated to precipitate tiny tetragonal crystal showing high fracture toughness and strength to be employable as heat resistant and structural materials. ${ }^{10-12)}$ In particular, the fused $\mathrm{CaO}$ stabilized zirconia (CSZ), for which part is partially stabilized by $\mathrm{CaO}$, is typically used to fabricate the refractory product.

\footnotetext{
Corresponding author: Sang-Jin Lee

E-mail : lee@mokpo.ac.kr

Tel : +82-61-450-2493 Fax : +82-61-450-2498

ORCID

http://orcid.org/0000-0001-6803-5064
}

The green body of zirconia setter to be produced with such fused CSZ powder normally undergoes firing process by which the final product of setter would have $25 \%$ of porosity with the density of $4.2 \mathrm{~g} / \mathrm{cm}^{3}$. Refractory products made of zirconia show excellent corrosion resistance and resistance to thermal shock and higher degree of refractoriness and outstanding heat insulation properties owing to low thermal conductivity. Besides, it exhibits the most excellent characteristics as a container to melt down cobalt, platinum, uranium, and nickel etc. since it is not wet by these materials. The products of zirconia setter or crucible are used as a container for calcination or sintering at high temperature, for molten metals; since it is used repetitively in the environment, the durability and service life matters. The service life of zirconia products is particularly influenced by phase changes of zirconia and resulting changes in thermal expansion behavior. Therefore, the stability of zirconia setter seems to be in control by examining and controlling factors affecting stability of zirconia products; the factors affecting phase changes and thermal expansion behavior of zirconia during manufacturing process.

In the present study, the fused CSZ will be employed to identify effects of factors on the stability of zirconia products. The firing temperature, cool down condition, addition of $\mathrm{CaO}$ stabilizer, and addition of additives will be varied to determine effects thereof upon phase changes and thermal expansion behavior of zirconia setter. The results obtained therefrom are expected to be applicable in producing stabilized zirconia setter of excellent durability. 
Table 1. Chemical Composition of Fused CSZ (wt\%)

\begin{tabular}{ccccc}
\hline $\mathrm{ZrO}_{2}$ & $\mathrm{CaO}$ & $\mathrm{Al}_{2} \mathrm{O}_{3}$ & $\mathrm{SiO}_{2}$ & $\mathrm{Fe}_{2} \mathrm{O}_{3}$ \\
\hline 95.17 & 3.93 & 0.25 & 0.22 & 0.05 \\
\hline
\end{tabular}

\section{Experimental Procedure}

\subsection{Experiment method according to each factor}

The fused CSZ powder (SZCS2, Sanziang Advanced Materials Co., LTD, China), employed for the present study, is of $13 \mu \mathrm{m}$ of mean particle diameter. Chemical composition of the fused CSZ is presented in Table 1. It is a powder of $\mathrm{ZrO}_{2}$ containing $8 \sim 9 \mathrm{~mol}$ of $\mathrm{CaO}$, and tiny amount of $\mathrm{Al}_{2} \mathrm{O}_{3}$ and $\mathrm{SiO}_{2}$.

To produce zirconia setter or crucible, the forming and sintering process is necessary thus the $100 \mathrm{MPa}$ of uniaxial pressure was applied to the specimen and sintered at temperatures of $1,500^{\circ} \mathrm{C}$ and $1,550^{\circ} \mathrm{C}$ under normal pressure in the electric box furnace to examine degrees of phase changes after thermal treatment. Besides, to examine changes in phase transition and thermal expansion behavior in more detail according to the varied firing temperature, the temperature was elevated by $25^{\circ} \mathrm{C}$ from $1,500^{\circ} \mathrm{C}$ and then kept for $3 \mathrm{~h}$ and cooled down in the furnace.

For the characteristics of zirconia product after firing, the schedules of cool down were varied to examine changes in phase transition and thermal expansion behavior. For the case of specimen (a), it was thermally quenched by drawing out from the furnace after the cool down by the speed of $100^{\circ} \mathrm{C} / \mathrm{h}$ from $1,550^{\circ} \mathrm{C}$ to $600^{\circ} \mathrm{C}$ in the furnace, whereas for the case of specimen (b), it was cool down to the room temperature in the furnace after cool down by the speed of $20^{\circ} \mathrm{C} /$ $\mathrm{h}$ from $600^{\circ} \mathrm{C}$ to $400^{\circ} \mathrm{C}$, after the cool down by the speed of $100^{\circ} \mathrm{C} / \mathrm{h}$ from $1,550^{\circ} \mathrm{C}$ to $600^{\circ} \mathrm{C}$ in the furnace. For the case of specimen (C), it was cool down to the room temperature quickly in the furnace after the cool down by the speed of $100^{\circ} \mathrm{C} / \mathrm{h}$ from $1,550^{\circ} \mathrm{C}$ to $900^{\circ} \mathrm{C}$. The detail heating schedule is presented in Fig. 1.

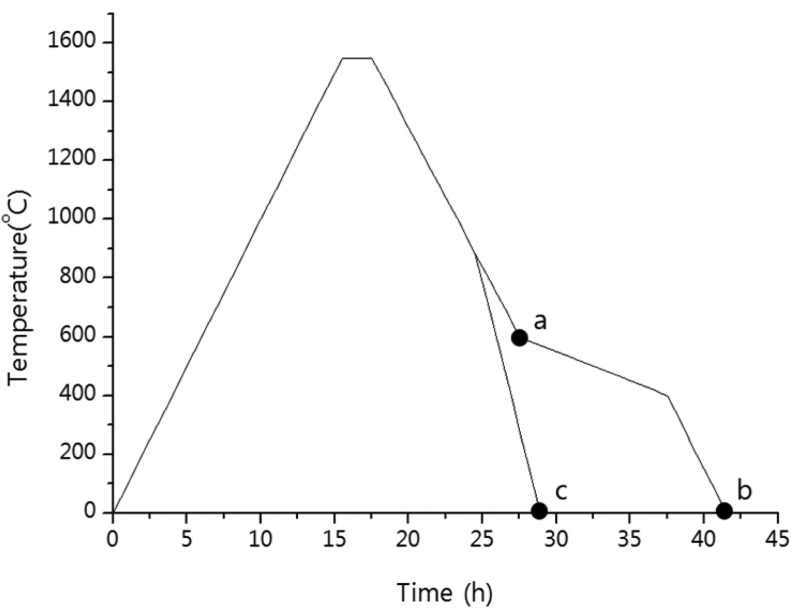

Fig. 1. Various heating and cooling curves for fabrication process of zirconia setter.
Table 2. Composition of Each Sample

\begin{tabular}{ccccc}
\hline \multirow{2}{*}{ Sample } & \multicolumn{3}{c}{ Batch composition (wt\%) } & Remark \\
\cline { 2 - 5 } & $\mathrm{CaCO}_{3}{ }^{\mathrm{a}}$ & $\mathrm{Al}_{2} \mathrm{O}_{3}{ }^{\mathrm{b}}$ & $\mathrm{YSZ}^{\mathrm{c}}$ & $\begin{array}{c}\mathrm{CaO} \text { Content } \\
\text { (wt\%) }\end{array}$ \\
\hline $\mathrm{Z} 1$ & 0.45 & - & - & 0.25 \\
$\mathrm{Z} 2$ & 0.9 & - & - & 0.50 \\
$\mathrm{Z} 3$ & 1.35 & - & - & 0.75 \\
$\mathrm{Z} 4$ & 1.80 & - & - & 1.00 \\
$\mathrm{Z} 5$ & 0.9 & 1 & - & 0.5 \\
$\mathrm{Z} 6$ & 0.9 & 3 & - & 0.5 \\
$\mathrm{Z} 7$ & 0.9 & - & 1 & 0.5 \\
$\mathrm{Z} 8$ & 0.9 & - & 3 & 0.5 \\
\hline
\end{tabular}

${ }^{\mathrm{a}} \mathrm{CaCO}_{3}$, Samchun Chemical Co., Ltd., Korea

${ }^{\mathrm{b}} \mathrm{A} 161 \mathrm{SG}$, Showa denko, Japan

${ }^{\mathrm{c}} \mathrm{GK}-3 \mathrm{YA}_{2} \mathrm{~B}_{1}$-A (Yttria Stabilized Zirconia), Jiangxi Kingan Hitech Co., Ltd., China

Since the liquation of $\mathrm{CaO}$, which was added as stabilizer, was expected from the zirconia crucible which was used for long time under high temperature, the $\mathrm{CaO}$ was added additionally to fused CSZ and the changes in thermal expansion coefficient by the addition was examined. $\mathrm{CaO}$ in $\mathrm{CaCO}_{3}$ was used and the amount of addition was varied from $0.25 \mathrm{wt} \%$ to $1.00 \mathrm{wt} \%$ for the experiment. Besides, tiny amount of $\mathrm{Al}_{2} \mathrm{O}_{3}$ was added to compare and examine changes in thermal expansion coefficient. $\mathrm{Al}_{2} \mathrm{O}_{3}$ of $1 \mathrm{wt} \%$ and $3 \mathrm{wt} \%$ were added for the experiment. Tiny amount of YSZ of 1 $\mathrm{wt} \%$ and $3 \mathrm{wt} \%$ were also added to examine changes in thermal expansion coefficient. The firing temperature for zirconia product, containing stabilizer and additives, was all controlled to be $1,550^{\circ} \mathrm{C}$. The each batch composition is presented in Table 2.

\subsection{Characterization}

Archimedes method was used to analyze bulk density, apparent porosity and water absorption of each sample. To measure the flexural strength (3 point bending), the universal testing machine (UTM 55689, INSTRON, U.K) was used for which the specimens of bar shape $(6 \times 8 \times 90 \mathrm{~mm})$ were prepared. At the level of loading of $10 \mathrm{KN}$, the test was carried out with the cross head speed of $5 \mathrm{~mm} / \mathrm{min}$.

To examine changing behaviors in crystal phases of produced specimens, the X-ray diffraction analyzer (Smart Lab, Rigaku, Japan) was employed for the analysis of phase changes in the condition of 0.02 degree scan speed from 10 to $802 \theta$ degrees. The relative phase fraction of zirconia was calculated by polymorph method. ${ }^{13)}$

And to examine thermal expansion behavior, the dilatometer (DIL 402 PC, Netzsch, Germany) was used in the interval of temperature measurement of room temperature $1,000^{\circ} \mathrm{C}$ at $5.0^{\circ} \mathrm{C} / \mathrm{min}$ heating schedule.

\section{Results and Discussion}

\subsection{Effects of thermal treatment}



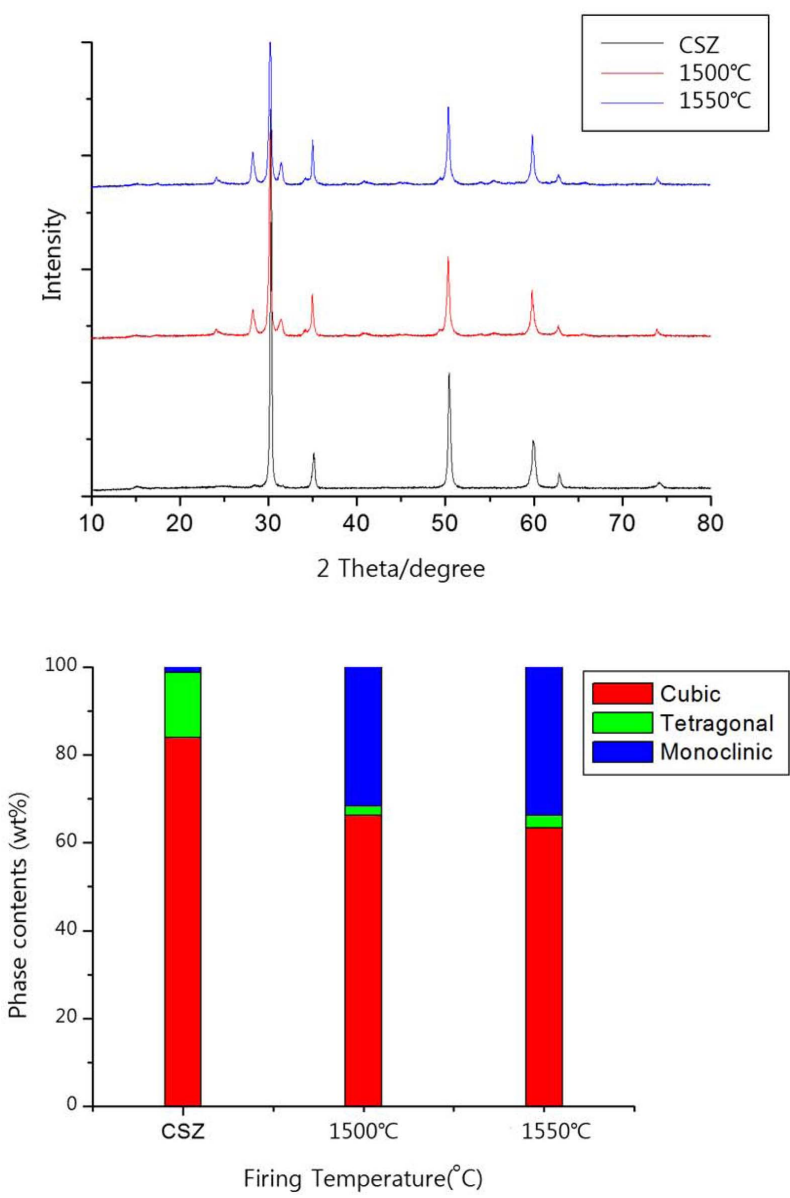

Fig. 2. XRD patterns and changes in ratio of phase transition of fused CSZ powder according to firing temperature.

The changes in ratio of cubic, tetragonal, and monoclinic phases, which are the polymorphism of zirconia, was found at firing temperature of the heat treatment process of zirconia setter made from fused CSZ powder. As illustrated in Fig. 2, the specimen, underwent the heat treatment process, exhibited the ratio of high temperature phase (cubic + tetragonal) decreased by $31 \%$ of $68.4 \%\left(1,500^{\circ} \mathrm{C}\right) \sim 66.3 \%$ $\left(1,550^{\circ} \mathrm{C}\right)$ comparing to the high temperature phase of starting powder of $98.8 \%$.

For the powder of fused CSZ, the production thereof undergoes melting, quenching, and pulverizing process. And the high temperature phase of fused powder remains a lot in the room temperature due to insufficient time for changes into low temperature phase (monoclinic) when the powder is quenched from its melting temperature of $2,500^{\circ} \mathrm{C}$ or over. However the firing and cool down in furnace to produce zirconia setter would have increased ratio of low temperature phase with the time sufficient for changes in phase transition. The increase of low temperature phase would be inevitable with the sintering process of the fused CSZ, and the strength of refractory product should be affected by the phase transition. The flexural strength of Z2 batch specimen, fired at temperature of $1,550^{\circ} \mathrm{C}$ presented in Table 2 ,
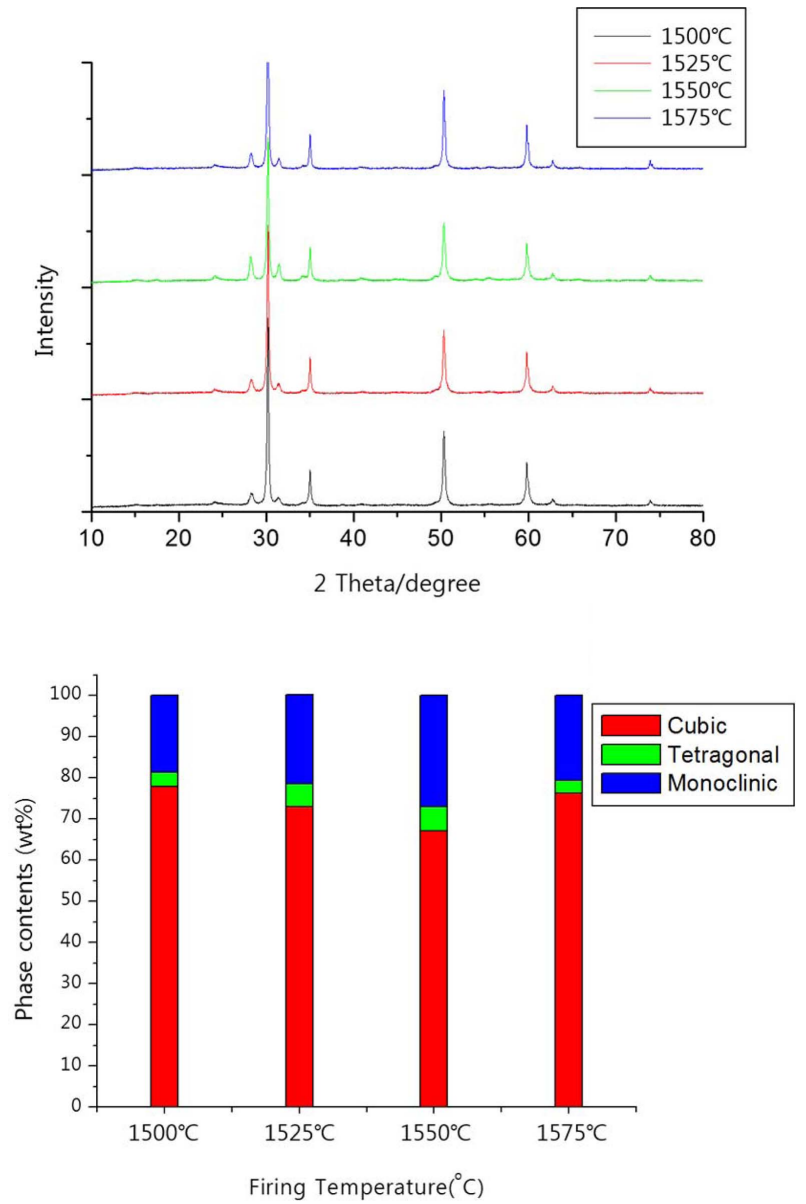

Fig. 3. XRD patterns and changes in ratio of phase transition of zirconia setter made from fused CSZ powder corresponded to continuous temperature increase.

was approximately $20.4 \mathrm{MPa}$ with apparent porosity and absorption ratio of $27.9 \%$ and $6.8 \%$, respectively.

Figure 3 illustrates XRD patterns and changes in the ratio of phase transition corresponded to continuous temperature increase. What was noticeable in the figure was the increase in low temperature phase in phase transition from temperature of $1,500^{\circ} \mathrm{C}$ by the increment of $25^{\circ} \mathrm{C}$, whereas in the temperature interval from $1550^{\circ} \mathrm{C}$ to $1575^{\circ} \mathrm{C}$, the high temperature phase increased instead. It was presumable that the sufficient time enabling the increase in low temperature phase was secured during the cool down in the furnace. However, the increase in high temperature phase at $1,575^{\circ} \mathrm{C}$ seems ascribable to manifestation of mechanism of stabilization by the increased solid solution of $\mathrm{CaO}$ in the structure of $\mathrm{ZrO}_{2}$ with the treatment at high temperature. $^{9)}$

The thermal expansion behaviors of different specimens of zirconia setter produced at different firing temperature are as presented in Fig. 4. Comparing to the low firing temperature of $1,500^{\circ} \mathrm{C}$, the specimens, produced at higher firing temperature tended to exhibit thermal expansion coefficient increasing distinctly with the varied slope of curves at the point of $800^{\circ} \mathrm{C}$; the slight behavior of thermal hysteresis was 


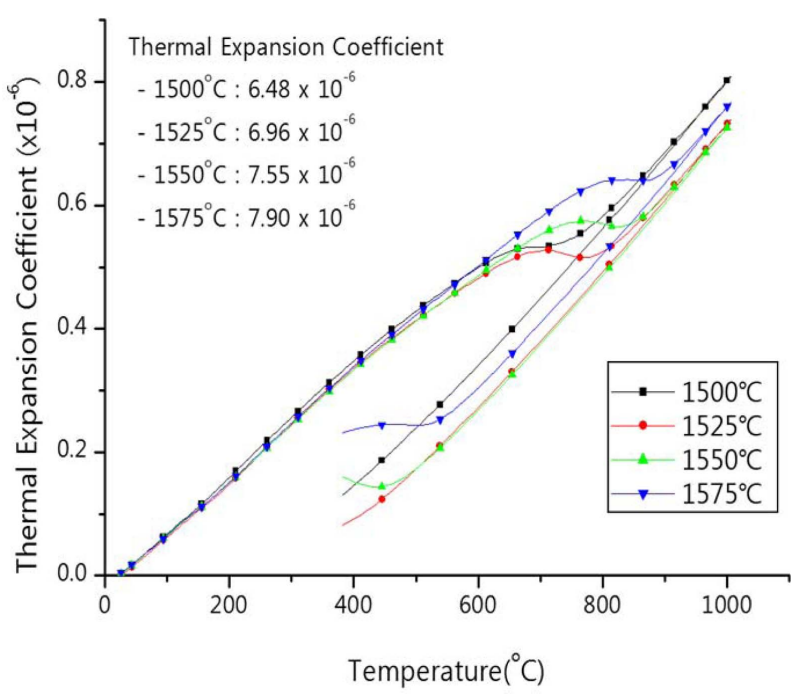

Fig. 4. Thermal expansion behavior of zirconia setter made from fused CSZ sintered at different temperatures.

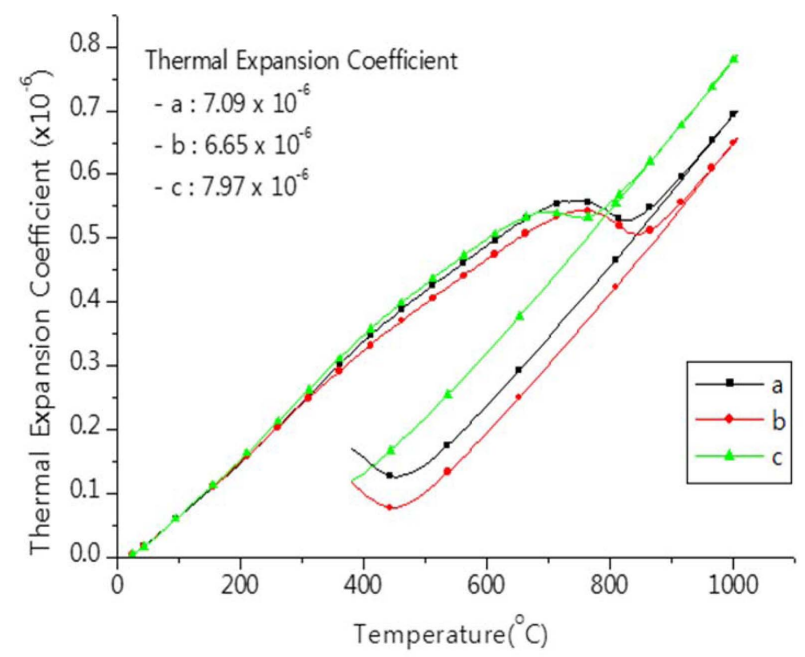

Fig. 5. Thermal expansion behavior of zirconia setter made from fused CSZ having different cooling schedule after sintering.

found from all specimens. ${ }^{14)}$

Varied behaviors of thermal expansion, owing to cool down conditions after heat treatment, are presented in Fig. 5 . For the case of (c) of fast cool down in the furnace from $900^{\circ} \mathrm{C}$, the thermal expansion coefficient of $0.5 \sim 1 \times 10^{-6} /{ }^{\circ} \mathrm{C}$ was higher than other conditions. Besides, in terms of the shape of graph, the occurrence of shape change was less than other cooling condition. Conditions of (a) and (b) differs from each other in terms of the cool down condition after $600^{\circ} \mathrm{C}$; for the case of slowed cool down (of the specimen of (b), the lower thermal expansion coefficient of $6.65 \times 10^{-6} /{ }^{\circ} \mathrm{C}$ was measured. Thus, depending on the conditions of cool down and taking out of specimen from furnace after firing, the zirconia refractory products made from fused CSZ exhibit differences in thermal expansion behavior, and the data thereof seem to be essential for the control of thermal properties of zirconia products.

\subsection{Effects of additives}

The effects of additives on the properties of zirconia setter were tested, and the firing shrinkage decreased in accordance with increasing content of $\mathrm{CaO}$ while the porosity and absorption increased. The increase in porosity was observed by simultaneous occurrence of sintering and solid solution. The results of examination on changes of physical properties and thermal expansion behavior of specimens according to varied contents of an addition of $\mathrm{CaO}$ are presented in Table 3 and Fig. 6, respectively. The thermal expansion coefficient increased in accordance with increasing content of $\mathrm{CaO}$; the increase in the thermal expansion coefficient seems ascribable to the increased degree of stabilization. ${ }^{15-18)}$

For the refractory products of zirconia which are supposed to be used for long time in high temperature, the loss of $\mathrm{CaO}$ due to liquation or reaction is expected, thereby the addition of sufficient $\mathrm{CaO}$ amount would be preferable, however, in

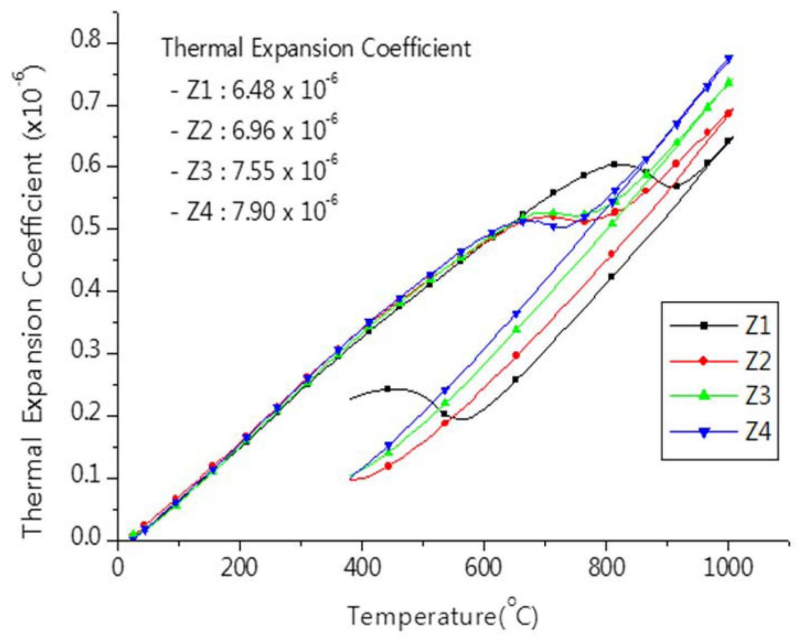

Fig. 6. Thermal expansion behavior of zirconia setter made from fused $\mathrm{CSZ}$ at different of $\mathrm{CaO}$ addition.

Table 3. Physical Property of Zirconia Setter Made from Fused CSZ at Different of CaO Addition

\begin{tabular}{cccccc}
\hline & Shrinkage (\%) & $\begin{array}{c}\text { Bulk Density } \\
\left(\mathrm{g} / \mathrm{cm}^{3}\right)\end{array}$ & $\begin{array}{c}\text { Apparent Porosity } \\
(\%)\end{array}$ & $\begin{array}{c}\text { Water Absorption } \\
(\%)\end{array}$ & $\begin{array}{c}\text { Flexural Strength } \\
(\mathrm{MPa})\end{array}$ \\
\hline $\mathrm{Z1}$ & 1.69 & 4.16 & 27.15 & 6.54 & 16.86 \\
$\mathrm{Z2}$ & 1.47 & 4.10 & 27.86 & 6.79 & 20.38 \\
$\mathrm{Z3}$ & 1.33 & 4.07 & 28.66 & 7.04 & 23.81 \\
$\mathrm{Z} 4$ & 1.23 & 4.05 & 29.02 & 7.17 & 29.89 \\
\hline
\end{tabular}



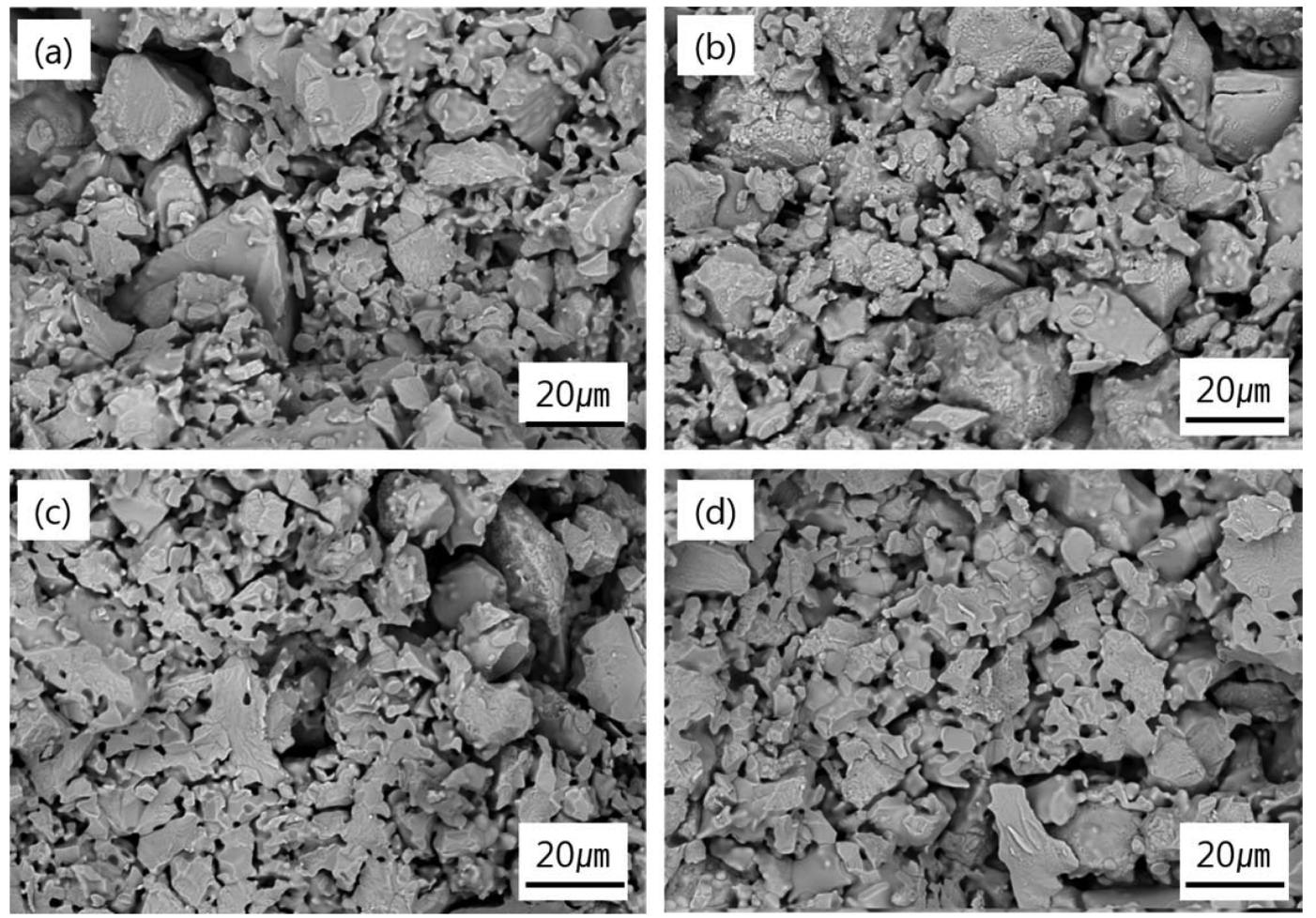

Fig. 7. Microstructures of sintered zirconia setter according to $\mathrm{CaO}$ addition amount : (a) $\mathrm{Z} 1$ (0.25 wt\%), (b) $\mathrm{Z} 2$ (0.50 wt\%), (c) $\mathrm{Z3}$ (0.75 wt\%) and (d) Z4 (1.00 wt\%).

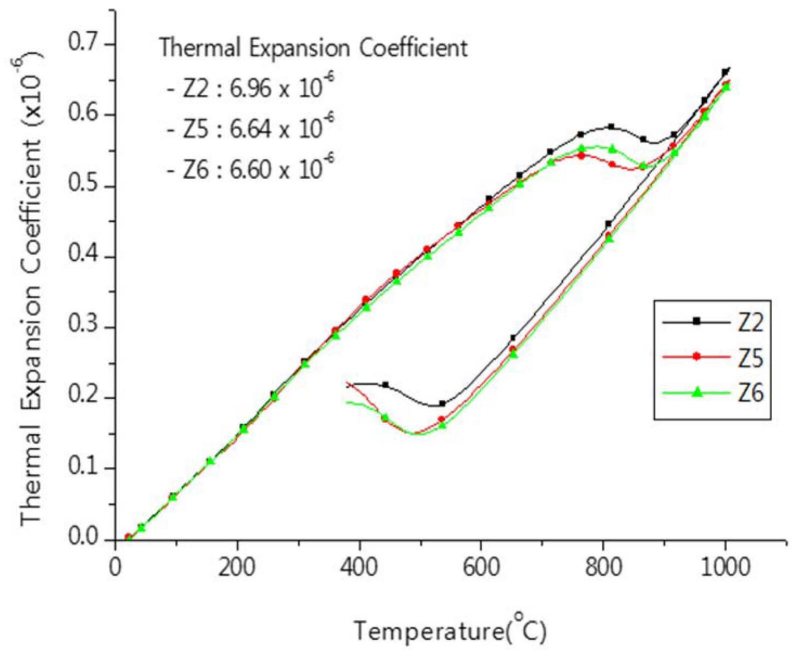

Fig. 8. Thermal expansion behavior of zirconia setter made from fused CSZ at different content of $\mathrm{Al}_{2} \mathrm{O}_{3}$ additive.

the case of excessive addition, the resistance to thermal shock would be decreased due to increase in thermal expansion coefficient (Fig. 6).

The microstructures of zirconia setter according to $\mathrm{CaO}$ addition amount are presented in Fig. 7. The porosity increased in accordance with increasing content of $\mathrm{CaO}$, however, the flexural strength increased (Table 3). This is due to the improvement of zirconia sinterability, which made strong and wide bonding between zirconia grains as shown in Fig. 7(d).

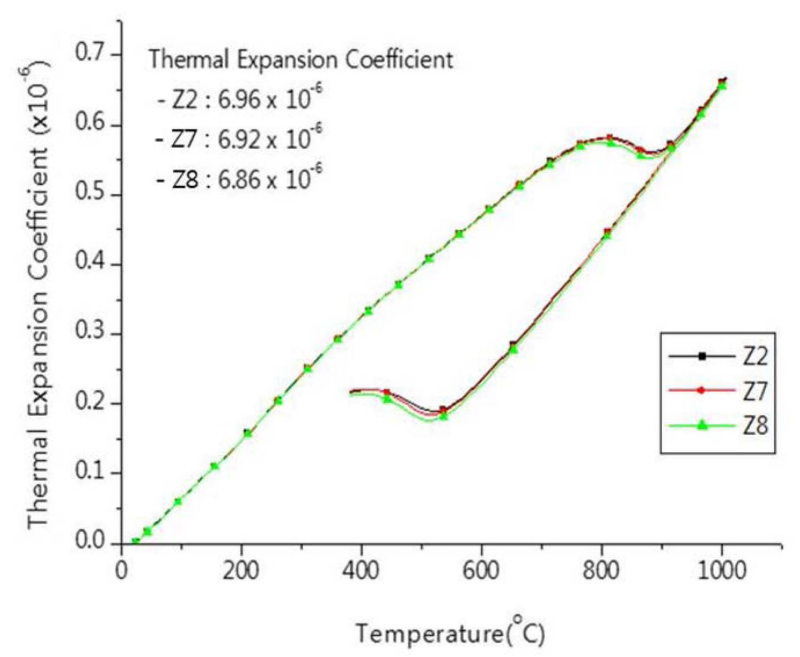

Fig. 9. Thermal expansion behavior of zirconia setter made from fused CSZ at different content of YSZ additive.

The results of examination of an addition of other additives such as $\mathrm{Al}_{2} \mathrm{O}_{3}$ and $\mathrm{YSZ}$ (yttria stabilized zirconia) are presented in Fig. 8 and Fig. 9. And the results of changes of physical properties of zirconia setter by the addition of $\mathrm{Al}_{2} \mathrm{O}_{3}$ are summarized in Table 4 . The ratio of firing shrinkage increased in accordance with increasing contents of $\mathrm{Al}_{2} \mathrm{O}_{3}$, while the porosity and absorption decreased. Thermal expansion coefficient was also appeared decreasing in accordance with increasing contents of $\mathrm{Al}_{2} \mathrm{O}_{3}$ (Fig. 8). The content of $\mathrm{Al}_{2} \mathrm{O}_{3}$ may not influence the stabilization of zirconia, how- 
Table 4. Physical Property of Zirconia Setter Made from Fused CSZ at Different Content of $\mathrm{Al}_{2} \mathrm{O}_{3}$ Additive

\begin{tabular}{cccccc}
\hline & Shrinkage (\%) & $\begin{array}{c}\text { Bulk Density } \\
\left(\mathrm{g} / \mathrm{cm}^{3}\right)\end{array}$ & $\begin{array}{c}\text { Apparent Porosity } \\
(\%)\end{array}$ & $\begin{array}{c}\text { Water Absorption } \\
(\%)\end{array}$ & $\begin{array}{c}\text { Flexural strength } \\
(\mathrm{MPa})\end{array}$ \\
\hline $\mathrm{Z} 5$ & 2.20 & 4.20 & 25.35 & 6.04 & 20.06 \\
$\mathrm{Z} 6$ & 2.36 & 4.21 & 25.04 & 6.06 & 21.53 \\
\hline
\end{tabular}

Table 5. Physical Property of Zirconia Setter Made from Fused CSZ at Different Content of YSZ additive

\begin{tabular}{cccccc}
\hline & Shrinkage (\%) & $\begin{array}{c}\text { Bulk Density } \\
\left(\mathrm{g} / \mathrm{m}^{3}\right)\end{array}$ & $\begin{array}{c}\text { Apparent Porosity } \\
(\%)\end{array}$ & $\begin{array}{c}\text { Water Absorption } \\
(\%)\end{array}$ & $\begin{array}{c}\text { Flexural strength } \\
(\mathrm{MPa})\end{array}$ \\
\hline $\mathrm{Z} 7$ & 1.50 & 4.08 & 28.35 & 6.97 & 17.80 \\
$\mathrm{Z} 8$ & 1.52 & 4.15 & 27.03 & 6.51 & 18.26 \\
\hline
\end{tabular}
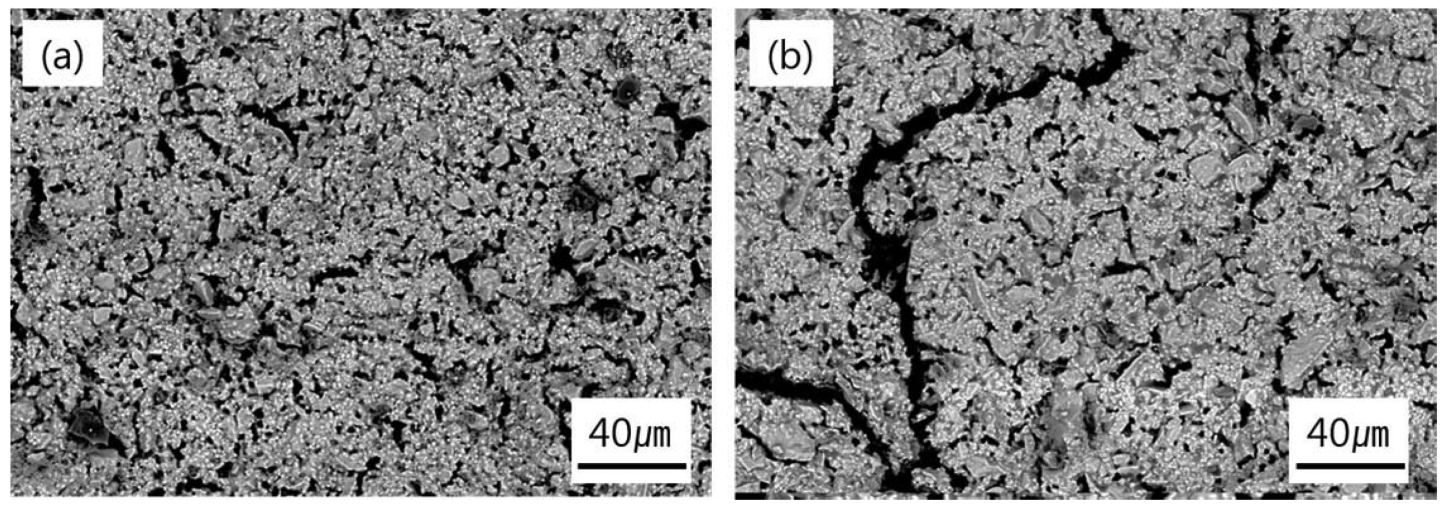

Fig 10. Microstructures of zirconia setter made from fused CSZ and repeatedly exposed to high temperature : (a) addition of $0.50 \mathrm{wt} \% \mathrm{CaO}$ and slowly cool down at every cycle and (b) without any addition and cool down to the room temperature quickly at every cycle.

ever, the sinterability of zirconia improved ${ }^{10)}$ and the thermal expansion coefficient decreased by the effect of $\mathrm{Al}_{2} \mathrm{O}_{3}$ which has a relatively lower thermal expansion coefficient. For the addition of YSZ, the behavior of thermal expansion (Fig. 9) did not exhibit significant changes before and after of the addition, with thermal expansion coefficient and the shape of inflection similar to each other; the thermal expansion coefficient decreased slightly by the addition of additive content of $3 \mathrm{wt} \%$. The changes in shapes of graph were hardly observed despite the addition of YSZ having high stabilization. The results of changes of physical properties of zirconia setter by the addition of YSZ are summarized in Table 5.

Finally, the microstructures of zirconia setter repeatedly exposed to high temperature are shown in Fig. 10. The zirconia setter added $0.50 \mathrm{wt} \% \mathrm{CaO}$ and slowly cooled down at every cycle showed no notable cracks in the microstructure. However, the zirconia setter without $\mathrm{CaO}$ addition and cooled down to the room temperature quickly at every cycle revealed micro cracks caused by thermal shock.

\section{Conclusions}

The properties of zirconia setter made from fused CSZ were examined by changing firing temperature, cool down condition, types of additives, and the amount of addition of additives which were expected to be influencing phase transition and thermal expansion behavior. The relative ratio of high temperature phase of zirconia was changed, and affected the stabilization of zirconia product with these varied factors. The durability and service life of zirconia setter were expected to be improved by controlling these factors, since the changes in phase transition or thermal expansion behavior would affect the occurrence of micro cracks depending on the fabrication process or long-term use under high temperature. In conclusion, the low sintering temperature around $1550^{\circ} \mathrm{C}$, maintaining slowed cool down condition, and the addition of $\mathrm{CaO}$ of appropriate amount together with $\mathrm{Al}_{2} \mathrm{O}_{3}$ resulted in increase of the stabilization of zirconia setter and decrease of the rapid change in thermal expansion for improvement of thermal shock.

\section{REFERENCES}

1. P. Duwez, F. Odell, and F. H. Brown, "Stabilization of Zirconia with Calcia and Magnesia," J. Am. Ceram. Soc., 359 [5] 107-13 (1952).

2. V. S. Stubican and S. P. Ray, "Phase Equilibria and Ordering in the System $\mathrm{ZrO}_{2}-\mathrm{CaO}$," J. Am. Ceram. Soc., 60 [11-12] 534-37 (1977). 
3. F. F. Lange, "Transformation Toughening, Part 1," $J$. Mater. Sci., 17, 225-34 (1982).

4. R. C. Garvie and P. S. Nicholson, "Structure and Thermomechanical Properties of Partially Stabilized Zirconia in the $\mathrm{CaO}-\mathrm{ZrO}_{2}$ System," J. Am. Ceram. Soc., 55 [3] 152-57 (1972).

5. J. Y. Kim, K. H. Hawng, and H. Kim, "Effect of Metastable Tetragonal $\mathrm{ZrO}_{2}$ Phase on the Mechanical Properties in $\mathrm{Al}_{2} \mathrm{O}-\mathrm{ZrO}_{2}$ System," J. Korean Ceram. Soc., 21 [2] 14955 (1984).

6. S. B. Jeon and S. I. Pyun, "Preparation and Characterization of Stabilized $\mathrm{ZrO}_{2}$ by Wet Chemical Methods," $J$. Korean Ceram. Soc., 16 [3] 155-63 (1979).

7. J. J. Kim, "Mechanical Properties and Microstructural Evolution Related to Phase Transformation in Partially Stabilized Zirconia Ceramics," Sci. Technol. Ceram. Mater., 3 [3] 217-23 (1988).

8. A. H. Heuer and M. Ruhle, "Phase Transformation in $\mathrm{ZrO}_{2}$ Containing Ceramics: I the Instability of C- $\mathrm{ZrO}_{2}$ and the Resulting Diffusion-Controlled Reaction," pp. 1-13 in Advances in Ceramics, Vol. 12, Science and Technology of Zirconia II, Ed. by A. H. Hever, N. Claussen and M. Ruhle, Am. Ceram. Soc. Press, Columbus, 1984.

9. D. L. Porter and A. H. Heuer, "Microstructural Development in MgO-Partially Stabilized Zirconia (Mg-PSZ)," J. Am, Ceram. Soc., 62 [5-6] 298-308 (1979).
10. K. H. Hwang and H. Kim, "The Study on the Improvement of the Strength and the Thermal Shock Resistance of $\mathrm{Al}_{2} \mathrm{O}_{3}-\mathrm{ZrO}_{2}$ Composites," J. Korean Ceram. Soc., 25 [3] 225-30 (1988).

11. R. C. Garvie, R. H. Hannink, and R. T. Pascoe, "Ceramic Steel?," Nature, 258 [5537] 703-704 (1975).

12. D. L. Porter, A. G. Evans, and A. H. Heuer, "Transformation-Toughening in Partially Stabilized Zirconia (PSZ)," Acta Metall., 27 [10] 1649-1654 (1979).

13. R. C. Garvie and P. S. Nicholson, "Phase Analysis in Zirconia Systems," J. Am. Ceram. Soc., 55 [6] 303-305 (1972)

14. D. H. Lee, T. W. Kim, K. S. Lee, and C. Kim, "Thermal Shock Resistance of Bilayered YSZ Thermal Barrier Coating," J. Korean Ceram. Soc., 55 [5] 452-60 (2018).

15. B. C. Weber, H. J. Garrett, F. A. Mauer, and M. A. Schwartz, "Observations on the Stabilization of Zirconia," J. Am. Ceram. Soc., 39 [6] 197-206 (1956).

16. T. Yamauchi and S. Somiya, "A Study on the Stabilization of Zirconia," J. Jpn. Ceram. Soc., 64 [722] 57-66 (1956).

17. S. I. Pyun, "About Stabilized Zirconia," J. Korean Ceram. Soc., 13 [4] 44-9 (1976).

18. K. C. Park and Y. S. Choi, "A Study on Microstructure and Phase Transformation of Sintered Body in $\mathrm{CaO}-\mathrm{ZrO}_{2}$ System,” J. Korean Ceram. Soc., 20 [3] 217-26 (1983). 